\title{
Pericyte-targeting drug delivery and tissue engineering
}

\author{
This article was published in the following Dove Press journal: \\ International Journal of Nanomedicine \\ 27 May 2016 \\ Number of times this article has been viewed
}

\section{Eunah Kang' \\ Jong Wook Shin²}

'School of Chemical Engineering and Material Science, ${ }^{2}$ Division of Allergic and Pulmonary Medicine, Department of Internal Medicine, College of Medicine, Chung-Ang University, Dongjak-Gu, Seoul, South Korea
Correspondence: Eunah Kang School of Chemical Engineering and Material Science, Chung-Ang University,

22I Heukseok-Dong, Dongjak-Gu, Seoul, South Korea

Tel +82 28206684

Email eakangek@cau.ac.kr

Jong Wook Shin

Department of Internal Medicine, Division of Allergic and Pulmonary Medicine,

College of Medicine, Chung-Ang

University, 22I Heukseok-Dong,

Dongjak-Gu, Seoul, South Korea

Tel $+8226299 \mid 407$

Fax +82 262991448

Email basthma@cau.ac.kr
Abstract: Pericytes are contractile mural cells that wrap around the endothelial cells of capillaries and venules. Depending on the triggers by cellular signals, pericytes have specific functionality in tumor microenvironments, properties of potent stem cells, and plasticity in cellular pathology. These features of pericytes can be activated for the promotion or reduction of angiogenesis. Frontier studies have exploited pericyte-targeting drug delivery, using pericytespecific peptides, small molecules, and DNA in tumor therapy. Moreover, the communication between pericytes and endothelial cells has been applied to the induction of vessel neoformation in tissue engineering. Pericytes may prove to be a novel target for tumor therapy and tissue engineering. The present paper specifically reviews pericyte-specific drug delivery and tissue engineering, allowing insight into the emerging research targeting pericytes.

Keywords: pericytes, pericyte-targeting drug delivery, tissue engineering, platelet-derived growth factor, angiogenesis, vascular remodeling

\section{Introduction}

Pericytes (PCs) have recently attracted attention due to the possibility of them acting in a similar manner to multipotent stem cells and as a result of their involvement in specific functions within tumor microenvironments. ${ }^{1-3}$ Traditionally, PCs have not been clearly classified due to the lack of PC-specific markers. PCs are mural cells that are embedded within vascular basement membranes, and are often referred to as microvascular periendothelial mesenchymal cells, including smooth muscle cells. ${ }^{2}$ The term "pericytes" was first introduced by Zimmermann, and denoted the cells commonly located on vessel outer walls. ${ }^{4,5}$ PCs are, in general, located on the basal membrane around the endothelial cell (EC) layer of small blood vessels, and between the intima and media of large vessels composed of three layers (intima, media, and adventitia). Intima is composed of ECs surrounding the vascular lumen. Media is mainly composed of smooth muscle cells, and adventitia is composed of fibroblasts and collagen fibrils. PCs are located between the intima and the media in large vessels and around the endothelial layer in small vessels. Upon observation, PCs are highly elongated and branched cells that extend circumferentially or longitudinally around vessel walls. The main features of PCs are plasticity and oncogenicity, although it is still not clear whether plasticity is caused by the transdifferentiation between different cell types or different functional roles under dynamic biochemical modulation of cell states.

Macroscopically, PCs appear to be located near to ECs. Under a microscope, however, it can be seen that PCs are physically connected to ECs by cell junctions (tight, gap, adherence junction in socket junctional complex), through which they communicate using various paracrine signals. Paracrine signal modulation between PCs and 
ECs controls cellular metastasis, the multilineage plasticity of PCs, vascular remodeling, and further angiogenesis. This specific cellular physiology of PCs has been classified previously in many reviews. ${ }^{2,6-9}$

Recently, PCs have been investigated with respect to tissue engineering and PC-targeting drug delivery for the promotion or inhibition of angiogenesis. Potential types of targeting delivery and the PC activation/regression are presented with graphical illustration in Figure 1. Although PC plasticity and other properties are still under investigation, the ability to control PCs in order to inhibit angiogenesis or encourage vascular remodeling is an attractive potential of target treatment. A plethora of research has employed the concept of biomaterials with target moieties and tissue engineering to investigate the interaction between ECs and PCs in a confined model system. This research gives an insight

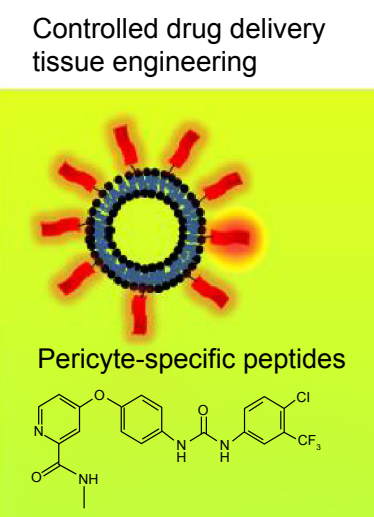

Small chemicals

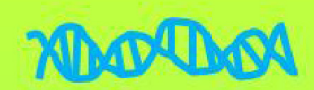

Pericyte-specific DNA

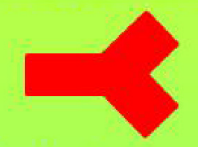

Pericyte-specific antibody

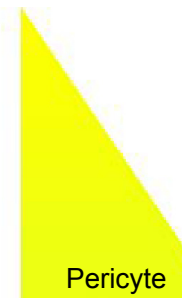

regression

Antiangiogenesis tumor inhibition

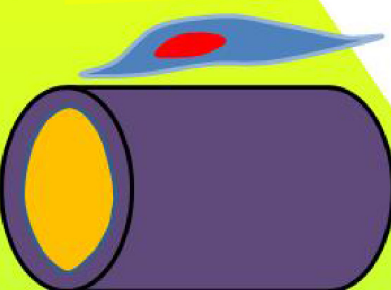

VEGF
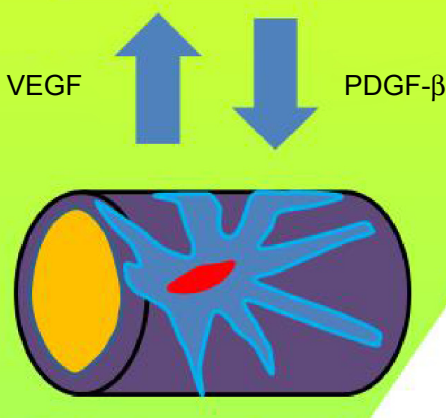

Pericyte activation

Angiogenesis vascular remodeling

Figure I Graphical illustration of pericytes' recruitment and their potential targeting delivery.

Notes: Pericytes are regressed or activated depending on the up- and downregulation of VEGF and PDGF- $\beta$ mainly. Targeting tools of pericytes are diverse as a form of peptides, small chemical molecules, DNA, and antibody, exploiting overexpressed marker on the pericyte cellular membrane or blocking the pathway of PDGFR- $\beta^{+}$under tumor microenvironment.

Abbreviations: PDGF- $\beta$, platelet-derived growth factor $\beta$; PDGFR- $\beta^{+}$, platelet-derived growth factor receptor $\beta$-positive; VEGF, vascular endothelial growth factor. 
into the possible future of the PC-targeted therapeutics and PC-employed tissue engineering, which are discussed in detail.

\section{PCs in vascular remodeling}

Hyperplasia is often seen in the denuded microvascular region, showing abnormal differentiation of smooth muscle. Cellular migration of adventitia may be related to the plasticity and the stem cell progenitor properties of PCs. Chen et $\mathrm{al}^{10}$ studied microvascular PCs within human myocardium and showed multiple PC-positive potencies similar to their spatial and functionally developmental region. Fetal and adult human heart PCs express canonical PC markers in situ, including CD146, neural/glial antigen 2 (NG2), platelet-derived growth factor receptor $\beta$ (PDGFR- $\beta$ ), PDGFR- $\alpha, \alpha$-smooth muscle actin ( $\alpha$ SMA), and smooth muscle myosin heavy chain. Neonatal cardiomyocyte coculture in vitro, and intramyocardial transplantation in vivo, showed a low fraction of cardiomyotic differentiation, suggesting anatomical restriction in the developmental potential of PCs as native mesenchymal stem cells. In addition, induction of the $\mathrm{G}$ protein signaling five regulator in PCs coincides spatially with active vascular remodeling during neovascularization, as reported by Berger et al. ${ }^{11}$

Tigges et $\mathrm{al}^{12}$ investigated whether PC-like cells or mesenchymal stem cells from the adventitia contribute injured vessels to restenosis. PC-like cells expressing the PC markers NG2, PDGFR- $\beta$, and CD146 were increased in the adventitia of injured femoral arteries compared with the group of uninjured femoral arteries in a mouse model. Adventitial PC-like cells also appeared in the restenoic neointima. These PC-like cells were originally derived from the local sites of the adventitia itself by residential adventitial PC-like cells, which are a distinct cell population in the restenotic process.

PCs migrate in response to stress or injury to the vascular wall. ${ }^{13}$ PCs also have multipotent differentiation capacity into vascular smooth muscle cells. In wound healing and inflammatory processes, PCs are also differentiated into collagen type I-producing fibroblasts. The mechanism of vascular remodeling is not clearly understood following atherosclerosis and stent insertion due to the spatially limited local injury in coronary arteries. Treatment of restenosis has been carried with drug-eluting stents in order to remove abnormal hyperplasia occurred at vascular remodeling. Drug-eluting stents that inhibit the proliferation of smooth muscle cells are routinely used for the treatment of atherosclerosis and coronary artery occlusion. Following insertion of a drug-eluting stent, in the long term, retarded formation of an endothelial layer and thrombus often occurs in the local region. ${ }^{14}$ Drug-eluting stents to nonspecifically inhibit cell proliferation and abnormal migration are loaded with anticancer drugs such as rapamycin and paclitaxel. These anticancer drugs are mainly focused on inhibiting the migration of smooth muscle cells without recovery of the EC layer. Although close communication between ECs and PCs is evidenced through close physical junctions and paracrine secretion with respect to biochemical signaling, PC-targeting treatment has been less exploited for stent combinatory drug delivery. PC-specific drug delivery may be a key alternative to resolve unfavorable vascular remodeling and maturation. Recent research regarding PCs in the myovascular anatomical region has shown that PCs themselves are directly related to hyperplasia of vascular remodeling, since ECs and $\mathrm{PCs}$ are closely related to paracrine signaling and physical contact. PC-like cells in the myovascular region may be a potential novel target of specific cell-controlled delivery.

\section{Interaction between PCs and ECs}

ECs function through suitable communication from cellular signals and their physical environment. Migration, proliferation, permeability, and contractibility of ECs are affected by paracrine signals and adjacent physical contact with PCs. PCs communicate with ECs by direct contact of gap and tight junctions in small vessels or paracrine signaling in large vessels. PCs and ECs play critical roles in EC differentiation, proliferation, and further vessel maturation and stabilization in both normal tissue and in tumor microenvironments. ${ }^{2}$ Factors including platelet-derived growth factor BB (PDGF-BB), angiopoetin-1, sphingosine 1-phosphate, and transforming growth factor $\beta$ (TGF- $\beta$ ) are exploited to control the recruitment and attachment of PCs to endothelium. Interestingly, the ratio of ECs to PCs varies from 1:1 in neural tissue to 10:1 in skeletal muscle, which makes PCs attractive for investigation in the field of tissue engineering. ${ }^{15}$

An isolated model for investigating the specific interaction between ECs and PCs has been demonstrated using a threedimensional microfluidic system by Kim et al. ${ }^{16}$ Compared with monoculture of ECs, coculture of PCs and ECs showed an increased number of junctions and branches, reduced diameter, and decreased permeability. Defined coculture and microfluidic model system of ECs, and PCs may be employed further to effectively screen PC-specific drugs for their effect on various biochemical factors. Moreover, PC mobility adjacent to ECs, junction formation between PCs and ECs, and augmented secretion of extracellular matrix can facilitate 

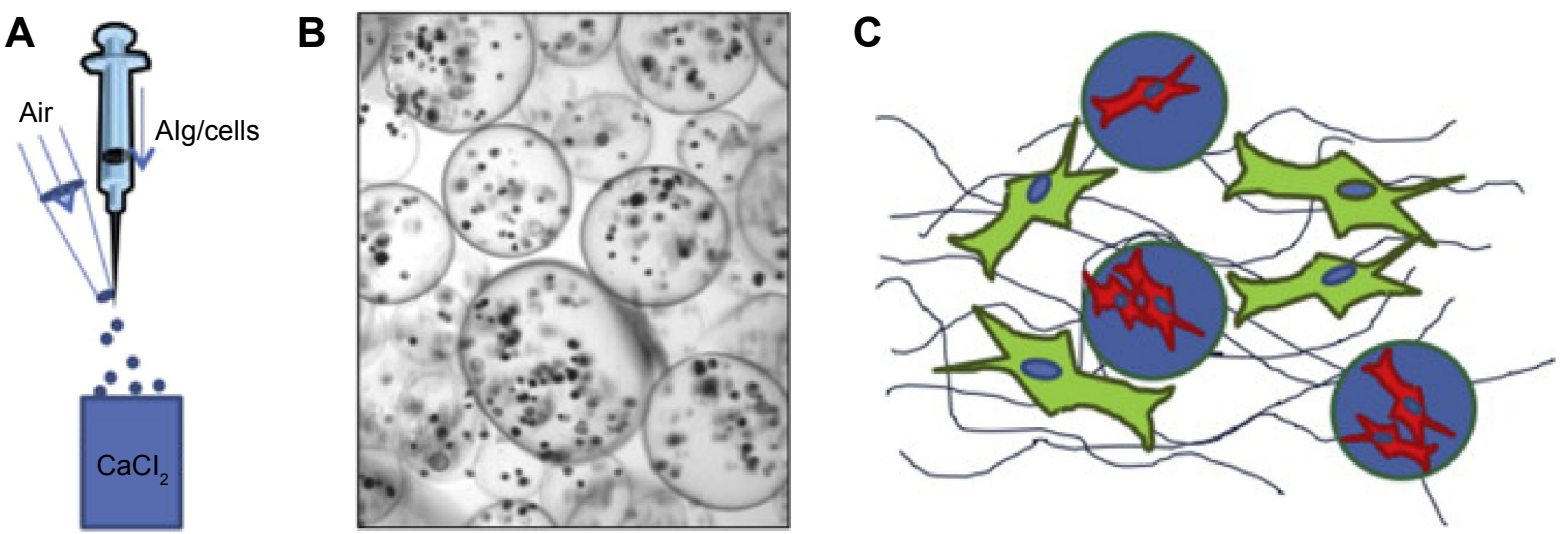

Figure 2 Pericyte tissue engineering with suspended ECs.

Notes: (A) The process of pericyte cell encapsulation. (B) Pericytes encapsulated in an alginate microgel reservoir. (C) The communication between suspended ECs and pericytes within alginate microgel by paracrine cellular signals makes the rearrangement of suspended ECs possible, reconstructing three-dimensional remodeling. Reprinted from Biomaterials, 34, Andrejecsk JW, Cui J, Chang WG, Devalliere J, Pober JS, Saltzman WM, Paracrine exchanges of molecular signals between alginate-encapsulated pericytes and freely suspended endothelial cells within a 3D protein gel, 8899-8908, Copyright (20I3), with permission from Elsevier. ${ }^{17}$

Abbreviation: ECs, endothelial cells.

the exploitation of specific angiogenic factors in engineered biomimetic three-dimensional microfluidic systems.

Three-dimensional microvasculature and mature vascular formation in tissue engineering has been attempted by the use of alginate gel bead-encapsulated PCs. ${ }^{17}$ Paracrine exchange of molecular signals between alginate-encapsulated PCs and freely suspended ECs resulted in three-dimensional self-regulation in target regenerative tissue (Figure 2). The alginate gel offered a safe cage to the PCs and a reservoir for the cellular paracrine signals to communicate with ECs. Paracrine signals released from alginate gel-encapsulated PCs led to the self-formation of a vascular network by the suspended ECs. The close relationship between the functional PCs and ECs may further be exploited in combination with the diverse existing biomaterials.

\section{PC-specific receptors and proteins}

PCs are present in different organs and tumors, and they possess a diverse heterogeneity in morphology and function. Although PC-positive markers have been exploited, no receptors or proteins completely specific to PCs, in any tissues or organs, have been discovered to date. Efforts to identify a single unique marker for the detection of all PCs are currently underway for full identification. ${ }^{5,7,18}$ However, PC plasticity makes its application difficult, since PCs can be changed with time-dependent maturation and tissue type. Most recently, expression of PC-specific receptors or proteins has been shown, including PDGFR- $\beta,{ }^{19}$ epidermal growth factor receptor, ${ }^{15,20}$ adenosine $\mathrm{A}_{2}$ receptors, ${ }^{21} \alpha \mathrm{SMA},{ }^{22,23}$ desmin, ${ }^{24} \mathrm{NG} 2$ proteoglycan, ${ }^{25,26}$ aminopeptidase A (APA) and aminopeptidase $\mathrm{N},{ }^{27,28}$ and regulator of $\mathrm{G}$ protein signaling 5 (RGS-5). ${ }^{6,11}$ These overexpressed markers in PCs are attractive targets to exploit in order to design novel therapeutics.

For instance, RGS-5, in particular, is highly expressed in perivascular cells of model tumor under the control of rat insulin promoter-transgenic mice tumors, and PDGFR- $\beta$-positive cells selectively upregulate RGS- 5 in the tumor microenvironment. ${ }^{11}$ The association between PC-positive markers and RGS-5 expression suggests relevant cellular pathology in vessel remodeling and in tumor-induced neovascularization. Also, TGF- $\beta$ signaling at the EC and PC interface has been known to block PC migration and to induce basement membrane deposition. TGF- $\beta$ signaling is also required for maintaining the direct physical contact between ECs and PCs. ${ }^{18}$ TGF- $\beta$-induced PC migration affects vascular retention, since $\mathrm{PC}$ alignment is loosened along the EC. Interestingly, $\alpha$ SMA-positive PCs were reduced by TGF- $\beta$ blockade, resulting in an increased penetration of nanoparticles into tumor tissue. ${ }^{29}$ This particular study indicates that PC coverage along the EC line and the adjusted PC mobility affects the enhanced permeability and retention of nanoparticle drugs. These various factors affecting PC recruitment, migration, and proliferation suggest the necessity to target controlled PC coverage on specific tissue and tumors. Moreover, it indicates that PC-specific factors may be candidates for potential drugs and regulators.

\section{PCs in the tumor microenvironment}

The complete cellular mechanism of PCs within the tumor microenvironment is still unclear. PCs can act as either a physical barrier or a promotive metastatic stimulator, depending on the particular cellular signals. PCs may actively promote metastasis by releasing factors that affect tumor 
invasion. Since PCs are closely related to EC stabilization, survival, and maturation in the normal vasculature, paracrine signaling between PCs and ECs may also have a major interaction in tumor vasculature. ${ }^{8} \mathrm{PC}$ are physically aligned with loosened EC association in tumor immature vascular structure, while PCs may act as a physical barrier that renders the extravasation of tumor cells to the vessel lumen more difficult. Before PCs are stabilized to form mature tumor vasculature, loose association with ECs, PC mobility, and overexpressed PC-positive markers indicates a strong contribution to tumor microvascular formation and angiogenesis. For this reason, PCs are a novel source of control of tumor angiogenesis and intercellular signaling with ECs. ${ }^{30}$

It is known that PC coverage is varied depending on the tumor phenotype, showing different responsiveness to chemotherapy. ${ }^{31,32}$ It has been demonstrated that PCs are present as a defective line in ovarian and colonic adenocarcinoma, while in pancreatic ductal adenocarcinoma and glioblastoma, they form glomeruloid structures. In most tumor types, PCs are present as a continuous line along ECs. The coverage density of PCs has relevance to the responsive effectiveness of chemotherapy. One study showed insight into the manner in which PC reduction may affect chemosensitivity to nanodrugs or nanoparticles. The authors explained that loosened PC alignment allowed high retention of nanoparticles by extravasation. Inhibition of TGF- $\beta$ signaling reduced $\alpha$ SMA-positive PCs, while accumulation of nanoparticles was enhanced in the tumor tissue. ${ }^{29}$ Structural varieties of PC coverage in blood vessels determine vascular wall density and sensitivity to chemotherapeutics.

PDGFR- $\beta$ activation is a major signal in the modulation of PC mobility. Several research papers have shown that inhibition of PDGF reduced tumor interstitial fluid pressure and increased transcapillary fluid exchange in the tumors. ${ }^{33,34}$ Furthermore, the codelivery effects of a PDGF aptamer were examined with commonly used anticancer drugs such as taxol and 5-fluorouracil, showing a high content of $3 \mathrm{H}$-taxol within tumor. It could not be directly concluded that effective up-take of anticancer drug was induced by vessel structural change, and thus occurred by PC modulation. However, considering that expression of the PDGF receptor is restricted to stromal and perivascular cells, PCs are closely related to vessel looseness, which increases the effectiveness

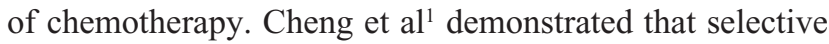
elimination of glioblastoma PCs (G PCs) in vivo led to the disruption of endothelial walls and collapsed vessel lumens, impairing glioblastoma tumor growth and progression. Selective elimination of G PCs was achieved with ganciclovir treatment in desmin promoter-driven herpes simplex virus thymidine kinase-transduced G PCs. Since ganciclovir is metabolized into a toxic agent in cells expressing herpes simplex virus thymidine kinase, selective apoptosis of $\mathrm{G}$ PCs was induced, which reduced tumor vessel formation and inhibited tumor growth.

These recent studies provide potential strategies to inhibit tumor growth by targeting selected PCs. The selective modulation of PCs by cellular signal blockage may be an attractive avenue in the development of PC-targeting drug delivery and tissue engineering. Tailored nanophysiology to control vascular structure suggests the development of nanoparticulate drugs, providing a strong rationale for PC-directed therapy.

\section{PC-targeting small molecules and combinatory drug delivery as antitumor therapy}

ECs are a widely accepted therapeutic target for the inhibition of angiogenesis in cancer therapies, while another vascular cell type, PCs, as a counterpart to ECs, has been rarely recognized as an alternative and critical target for cancer treatment. PCs are known to be related to angiogenesis and further metastasis by abnormal PC-EC interactions. PCs communicate with ECs by paracrine signals or physical contact of cell junctions. The abnormal plasticity, mobility, and morphological change in PCs cause undesired angiogenesis in tumors, and metastasis to the kidney, intestine, and local lymph nodes. ${ }^{35}$ In addition, cisplatin chemosensitivity was impaired in tumor spheroids of lung cancer in a perfused microfluidic platform, since a physical barrier was generated by PCs distributed around the tumor spheroids. $^{36}$

The control of PC regression or activation is closely related with angiogenesis and antiangiogenesis under tumor microenvironment. Targeting PCs for anticancer therapy involves different approaches, which are enhancement of anticancer drug efficacy using PC-overexpressed markers or the regulation of $\mathrm{PC}$ itself for antiangiogenesis. One way to PC targeting is to target overexpressed markers on PC cellular membrane, since PC is actively recruited under tumor microenvironment during microvessel formation. The drug delivery carrier with PC targeting marker can enhance delivery efficacy of conventional anticancer drug. The other way is to target PC itself, specifically to block PDGFR- $\beta$ on the PC membrane. The downregulation of PDGF or blockade of PDGFR- $\beta$ controls PC activity, reducing contractility, loosening junctions with ECs, and thus regressing PCs. In the blockade of PDGFR- $\beta$, several approaches were introduced, including the addition of competing molecules 
against PDGF, cascade blockade of PDGFR- $\beta$ using small proteinase inhibitor chemicals, and employment of scaffold to stabilize active allostatic sites. PC-targeting drug delivery as antitumor therapy appears to be a promising avenue for novel development. The frontier studies of PC-targeting drug delivery for each approach are listed in Table 1.

Several studies have shown examples of PC-targeting delivery with peptide moieties, the receptors of which are overexpressed on PCs, as shown in Figure 3. The membrane-associated protease, APA, is known to be active on perivascular cells, especially PCs, and has been shown to be associated with tumor blood vessels. ${ }^{37}$ The expression of APA has been shown to correlate with neoplastic progression. Using phase display, the small molecular peptide, CPRECES, which recognizes APA, was discovered and used as a potential therapeutic. The CPRECES peptide-decorated liposomal delivery system, loaded with doxorubicin, showed effective tumor regression and low toxicity. Another study demonstrated PC-specific drug delivery through the interaction with $\mathrm{PC}$-specific moieties on nanoparticles. ${ }^{38}$ The TAASGVRSMH peptide, TH10, was screened though phase display, and was shown to have a strong affinity for the NG2 proteoglycan on the PC membrane. TH10-decorated nanoparticles were demonstrated to display a strong affinity for the NG2 proteoglycan expressed on tumor vascular PCs, which facilitated enhanced internalization into cells and, thus, high delivery of docetaxel into the nucleus. Nanoparticles coated with PC-specific moieties showed enhanced PC death and inhibition of PC migration. In particular, TH10-decorated nanoparticles administered to $\mathrm{BALB} / \mathrm{c}$ mice harboring B16F1-luc-G5 lung metastases demonstrated a strong antiangiogenic effect by targeting the inhibition of PCs in the tumor vasculature. This therapeutic approach may be effective in the irradiation of the immature PCs during initial vessel formation and metastasis.

Table I Summary of molecules used for pericyte-targeting antiangiogenesis

\begin{tabular}{|c|c|c|c|c|c|}
\hline Pericyte specificity & Type & Target & Anticancer drug & Comments & References \\
\hline CPRECES peptide & $\begin{array}{l}\text { Peptide-conjugated } \\
\text { liposome }\end{array}$ & $\begin{array}{l}\text { Membrane-associated } \\
\text { protease, APA }\end{array}$ & Doxorubicin & $\begin{array}{l}\text { Targeted membrane docking } \\
\text { on the pericytes. Effective } \\
\text { doxorubicin delivery coordinated } \\
\text { with APA pericyte-targeting } \\
\text { marker }\end{array}$ & 37 \\
\hline $\begin{array}{l}\text { TAASGVRSMH } \\
(\mathrm{THIO})\end{array}$ & $\begin{array}{l}\text { Peptide-conjugated } \\
\text { liposome }\end{array}$ & $\begin{array}{l}\text { NG2 proteoglycan on } \\
\text { cell membrane }\end{array}$ & Docetaxel & $\begin{array}{l}\text { Targeted membrane docking on } \\
\text { the pericytes. Effective docetaxel } \\
\text { delivery coordinated with NG2 } \\
\text { pericyte-targeting marker }\end{array}$ & 38 \\
\hline $\begin{array}{l}\text { CSRNLIDC with } \\
\text { C-C disulfide bond }\end{array}$ & $\begin{array}{l}\text { Conjugation with } \\
\text { human serum } \\
\text { albumin }\end{array}$ & $\begin{array}{l}\text { PDGFR- } \beta \text { on tumor } \\
\text { cells }\end{array}$ & Doxorubicin & $\begin{array}{l}\text { Cyclic peptides, block PDGFR- } \beta \\
\text { on pericyte }\end{array}$ & 39,40 \\
\hline Valproic acid & $\begin{array}{l}\text { Histone } \\
\text { deacetylase } \\
\text { inhibitor }\end{array}$ & Block PDGFR & & $\begin{array}{l}\text { Blockade of the PDGFR- } \beta^{+} \\
\text {pericytes }\end{array}$ & 41 \\
\hline Imatinib & $\begin{array}{l}\text { Tyrosine kinase } \\
\text { inhibitor }\end{array}$ & Block PDGFR & & $\begin{array}{l}\text { Blockade of the PDGFR- } \beta^{+} \\
\text {pericytes }\end{array}$ & $42-44$ \\
\hline $\begin{array}{l}\text { Anti-olfactomedin- } \\
\text { like } 3\end{array}$ & Antibody & Antagonist to BMP4 & & $\begin{array}{l}\text { Antiangiogenesis and, thus, } \\
\text { induction of tumor regression }\end{array}$ & 45 \\
\hline SU6668 & $\begin{array}{l}\text { Tyrosine kinase } \\
\text { inhibitor }\end{array}$ & Block PDGFR & & $\begin{array}{l}\text { Cotargeting VEGF (SU54I6) and } \\
\text { PDGF }\end{array}$ & 46 \\
\hline $\begin{array}{l}\text { AXI02, PDGF } \\
\text { aptamer }\end{array}$ & ssDNA aptamer & Block PDGFR & Paclitaxel & $\begin{array}{l}\text { Bevacizumab codelivery targeting } \\
\text { VEGF and PDGF to control ECs } \\
\text { and pericytes }\end{array}$ & 48 \\
\hline $\begin{array}{l}\text { DNA-based aptamer } \\
\text { to PDGF- } \beta\end{array}$ & $\begin{array}{l}\text { DNA-based } \\
\text { aptamer conjugated } \\
\text { into PEG }\end{array}$ & Block PDGFR & Taxol & $\begin{array}{l}\text { Conjugating to polyethylene } \\
\text { glycol }\end{array}$ & 33,34 \\
\hline $\begin{array}{l}\text { Amino triazole } \\
\text { scaffold }\end{array}$ & & $\begin{array}{l}\text { To stabilize the } \\
\text { inactive allostatic site } \\
\text { of PRGFR- } \beta \text { and B-RAF }\end{array}$ & & & 42 \\
\hline
\end{tabular}

Abbreviations: APA, aminopeptidase A; BMP, bone morphogenetic protein; EC, endothelial cell; NG2, neural/glial antigen 2; PDGF, platelet-derived growth factor; PDGF- $\beta$, platelet-derived growth factor $\beta$; PDGFR, platelet-derived growth factor receptor; PDGFR- $\beta^{+}$, platelet-derived growth factor receptor $\beta$-positive; VEGF, vascular endothelial growth factor; PEG, polyethylene glycol. 
A

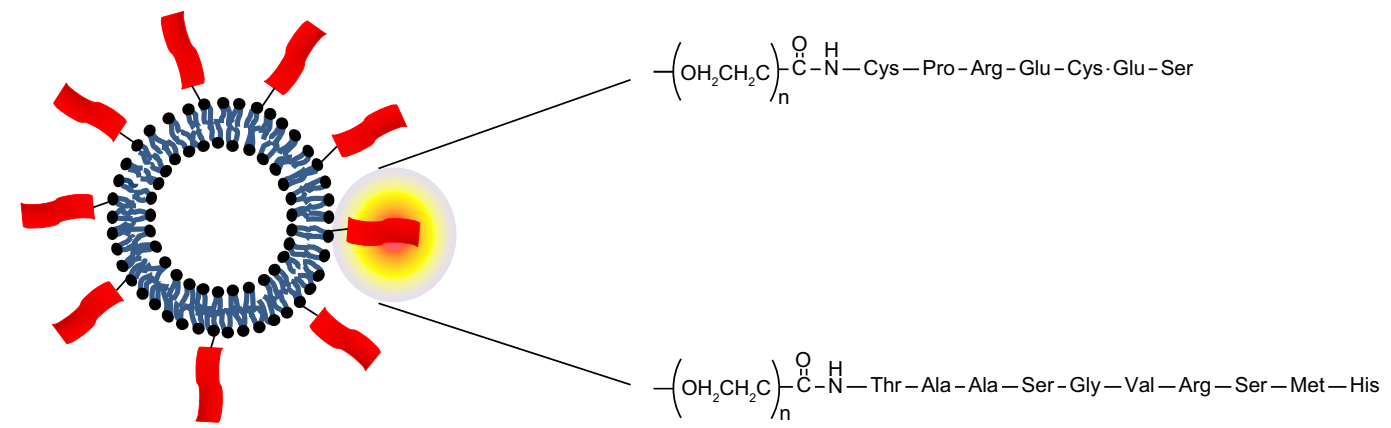

Pericyte-targeting peptides (CPRECES, TAASGVRSMH)

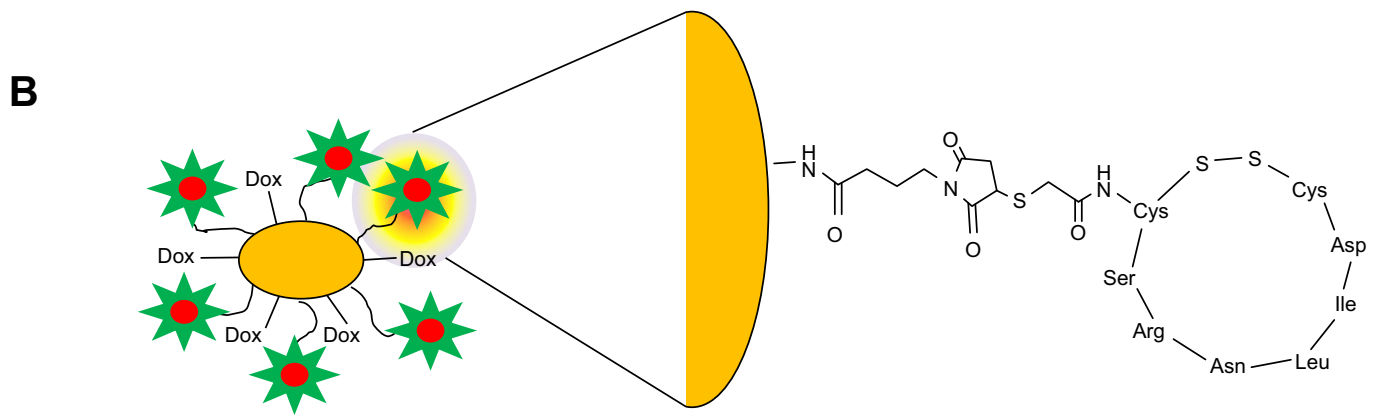

Figure 3 The design of pericyte-targeting delivery carriers.

Notes: (A) Lipid vesicles conjugated to pericyte-targeting peptide motifs; CPRECES to target membrane-APA and TAASGVRSMH (THI0) to target NG2 proteoglycan on pericyte cell membrane. (B) Protein carriers conjugated to a pericyte-targeting cyclic peptide, CSRNLIDC, to block PDGFR- $\beta$ under pericyte-developed tumor environment. Abbreviations: APA, aminopeptidase A; NG2, neural/glial antigen 2; PDGFR- $\beta$, platelet-derived growth factor receptor $\beta$; DOX, doxorubicin.

Prakash et al ${ }^{39,40}$ studied the targeting of tumor-associated PCs using overexpressed PDGFR- $\beta$ on malignant tumor cells. The cyclic peptide, CSRNLIDC, which binds to PDGFR- $\beta$, was chemically conjugated to human serum albumin (HSA). HSA also carried the anticancer drug, doxorubicin, by chemical conjugation. Interestingly, PDGFR-targeting cyclic peptide-labeled anticancer drug carriers were dramatically accumulated in PDGFR- $\beta$-expressing vascular PCs as well as in malignant stromal fibroblasts. The administration of PDGFR- $\beta$-targeting carriers loaded with doxorubicin resulted in markedly reduced tumor volume compared with that of PDGFR- $\beta$-targeting peptide-labeled HSA and doxorubicin only. The novel strategy of targeting PCs may be effective in imposing anticancer function.

Together with PC-targeting moieties of peptides, small molecules as PC-targeting drugs, such as valproic acid, imatinib, and sorafenib, were also investigated as antitumor therapies in several studies (Figure 4). ${ }^{41-44}$ Karen et al ${ }^{41}$ investigated the effects of PC-targeting small molecules, more specifically, whether valproic acid, a histone deacetylase inhibitor, influenced PC proliferation. Other small molecules including trichostatic A and 2-Et-4-Me-Penta were also tested in comparison with valproic acid. Valproic acid reduced the proliferation, migration, and differentiation of PCs, compared with chemical analogs or other histone deacetylase inhibitors. The discovery of PC-specific drugs has resulted in the ability to control PC-derived cellular phenomena including migration, proliferation, and differentiation. The efforts to synthesize novel small molecule drugs have increased since imatinib and sorafenib showed the potential to target PDGFR- $\beta$ and B-RAF, stabilizing inactive kinase conformations, thus disrupting only PC activity. ${ }^{42,44}$ As an example of PC-targeting synthetic small molecules, amino triazole scaffolds act at an allosteric conformational site on kinase due to hydrophobic and specific hydrogen bonding. Using an allosteric approach, synthesized novel small molecules with an amino triazole functional group selectively disrupted angiogenesis and tumor growth by stabilizing the inactive site of PRGFR- $\beta$ and B-RAF in orthotropic pancreatic and renal carcinoma models. ${ }^{42}$ This allosteric site-specific kinase inhibitor provides a strategy to fortify the narrow kinase specificity, compared with clinically approved kinase inhibitors with broad therapeutic windows.

Together with direct PC-targeting small molecules and short peptides, pathway-blocking protein antagonists can also be introduced as a novel platform for PC-targeting drug 
A

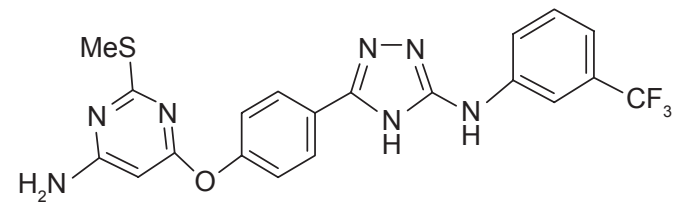

C

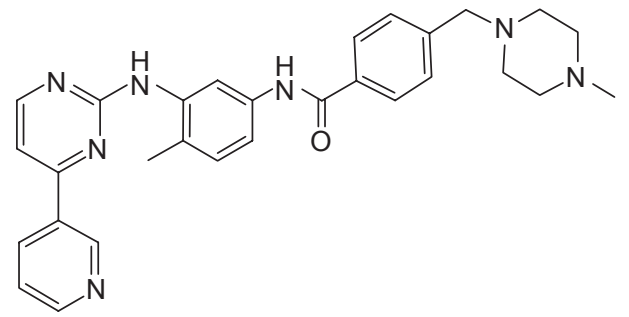

B

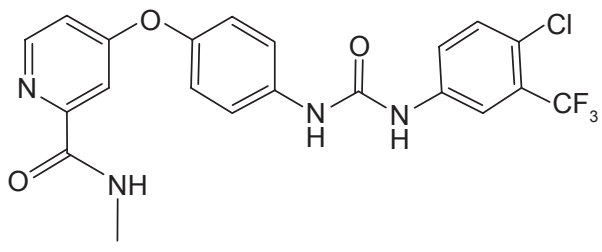

D

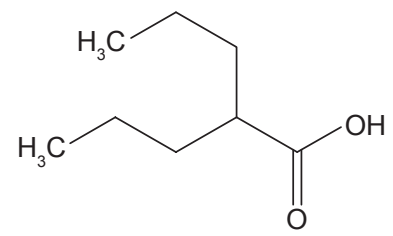

Figure 4 Pericyte-targeting small molecules that act at blockade of the PDGFR- $\beta^{+}$pericytes.

Notes: (A) 6 as chemical analog synthesized as tyrosine kinase inhibitor, (B) sorafenib as tyrosine kinase inhibitor, (C) imatinib as tyrosine kinase inhibitor, and (D) valproic acid as histone deacetylase inhibitor.

Abbreviation: PDGFR- $\beta^{+}$, platelet-derived growth factor receptor $\beta$-positive.

delivery. A study by Miljkovic-Licina et a ${ }^{45}$ demonstrated that olfactomedin like-3 (Olfm3) inhibited angiogenesis and PC coverage. Olfactomedin, a bone morphogenetic protein (BMP) antagonist, serves as a scaffold protein interacting with BMPs. BMP4 signaling is known to be critically involved in the development of blood vessels. Interestingly, Olfm3 expression is spatially coincident with $\alpha$ SMA- and NG2-positive staining in PCs of tumor vessels. Treatment with anti-Olfm 3 antibodies inhibited $\alpha$ SMA and NG2 expression, which ordinarily shows positive staining in tumor-bearing mice. Downregulation of BMP activity by interaction with anti-Olfm3 antibodies reduced angiogenesis and $\mathrm{PC}$ coverage in tumors.

Several studies have shown that cotargeting treatment of ECs and PCs may be much more effective in reducing tumor growth. ${ }^{46-48}$ Most antiangiogenic tumor therapy has been focused on preventing EC proliferation by targeting the vascular endothelial growth factor (VEGF) receptor. ${ }^{49,50}$ PCs that communicate with ECs and unbalance the paracrine signaling between these cells may be a candidate for an alternative tumor cotarget. VEGF and PDGF, and their receptors, have been used as targets for tumor therapy. Sennino et $a l^{47}$ showed that cotargeting the VEGF and PDGF receptors was beneficial in reducing vessel density, tumor growth, and, therefore, angiogenesis. The receptor tyrosine kinase inhibitors SU668 and imatinib block VEGFR and PDGFR, respectively, and were employed alone or in combination. Combined tumor therapy to block both VEGFR and PDGFR was much more effective in reducing the signal density of PC-positive markers (CD31, NG2, desmin, and $\alpha$ SMA). Results have indicated that cotargeting was effective for antiangiogenesis and $\mathrm{PC}$ reduction in antitumor therapy.
Another study reported codelivery of bevacizumab targeting ECs and the PDGF aptamer, AX102, targeting PCs. ${ }^{48}$ Cotargeting EC and PCs was much more effective in decreasing microvessel density, proliferating cell nuclear antigen, and vascular maturation, compared with EC-targeting monodelivery. The codelivery of bevacizumab and the PDGF aptamer, AX102, dramatically reduced tumor growth.

\section{PCs in tissue engineering}

Based on the understanding of their properties and functions, PCs have been used as a source of tissue engineering. ${ }^{51}$ Several cases have been noted in which PCs were incorporated into hydrogels and biomaterials with coculture of ECs in the areas of vascular grafts, cell sheets, and cell encapsulation. ${ }^{17,52-56}$ Mendes et $\mathrm{al}{ }^{55}$ showed that perivascularlike cells contributed to the stability of the vascular network of osteogenic tissue formed from cell sheet-based construction. The coculture combination of osteogenic, endothelial, and perivascular-like cells enhanced the vascularization of bone tissue engineering construction. It was observed that CD146-positive perivascular-like cells directly interacted with ECs, which may further facilitate vascular maturation and stabilization. Interestingly, the shape of perivascular-like cells cultured on an osteogenic substrate was modified from star-like to a cord-like structure. Cell-cell interaction, paracrine interaction, or mechanical environment may be recognizable factors to alter perivascular-like cells. The application of perivascular-like cells to cell sheets is potentially promising in the induction of vascularization in three-dimensional construction. Fuoco et al ${ }^{54}$ examined the three-dimensional polyethylene glycol-based hydrogel-encapsulated PCs for 
muscle tissue engineering. The stable hydrogel environment provided rejuvenation of aged PCs. Vasculogenesis and myogenesis of PCs may provide a novel regenerative approach. This study suggests that combinatory design with biomaterials and PCs can be developed for regenerative tissue engineering.

Saik et $\mathrm{al}^{56}$ studied polyethylene glycol-immobilized PDGF-BB hydrogel in order to stimulate PCs and to produce extracellular matrix proteins, fibronectin, collagen, and proteoglycans. Thus, angiogenesis stimulated by PCs in a tissueengineered microsystem formed the basement membrane of capillaries, although polyethylene glycol-immobilized PDGF-BB hydrogel may require clarification for multiple cellular responses, including release of matrix metalloproteinase-2 and -9 and PC stimulation. Polyethylene glycol-immobilized PDGF-BB hydrogel was an effective biomimetic scaffold for angiogenesis, specifically in vivo. A tissue-engineered microsystem to specifically target PCs could be an aim of controlled drug delivery and tissue engineering.

The advantages of targeting PCs have been evaluated for therapeutic efficacy as a novel source of PC-specific tissue engineering. However, the complicated and interactive functions of PCs need to be clarified in each heterogeneous tissue. Purified isolation of PCs by the development of specific PC-positive markers may overcome the limited application of PCs in tissue engineering.

\section{Perspectives in biomolecular pharmaceuticals to target PCs}

Universal PC-positive markers have not yet been identified in heterogeneous tissues, organs, or tumors. PC-targeted drug delivery has overcome hurdles for development in pharmaceutical and biomedical applications. Codelivery to target ECs/PCs or PCs/nonspecific tumor appears to be a potent approach to develop a new generation of therapeutics. Even monodelivery to target PCs is effective in reducing new vessel formation and angiogenesis. Recent studies have suggested the use of potency as a novel PC-targeting therapy. Yet, the combinatory design including small molecules, peptides, aptamers, and antibodies has rarely been investigated with respect to the development of PC-targeted drug delivery and tissue engineering. This review provides an insight into the novel delivery of PC-targeted therapy. Closely associated applications of ECs and PCs in biomolecular and pharmaceutical research should be further carried out in the novel target of vascular remodeling, antiangiogenesis, and tissue engineering. The concerns in the field of biomolecular and pharmaceutical research may shift from the current biological therapy to the targeting of PCs.

\section{Acknowledgment}

This research was supported by the Basic Science Research Program through the National Research Foundation of Korea (NRF), funded by the Ministry of Science, ICT \& Future Planning (NRF-2015R1C1A2A01053307).

\section{Disclosure}

The authors report no conflicts of interest in this work.

\section{References}

1. Cheng L, Huang Z, Zhou W, et al. Glioblastoma stem cells generate vascular pericytes to support vessel function and tumor growth. Cell. 2013;153:139-152.

2. Armulik A, Abramsson A, Betsholtz C. Endothelial/pericyte interactions. Circ Res. 2005;97:512-523.

3. Guichet PO, Guelfi S, Teigell M, et al. Notch1 stimulation induces a vascularization switch with pericyte-like cell differentiation of glioblastoma stem cells. Stem Cells. 2015;33:21-34.

4. Sims DE. The pericyte - a review. Tissue Cell. 1986;18:153-174.

5. Sims DE. Diversity within pericytes. Clin Exp Pharmacol Physiol. 2000; 27:842-846

6. Nishihara H. Human pathological basis of blood vessels and stromal tissue for nanotechnology. Adv Drug Deliv Rev. 2014;74:19-27.

7. Kelly-Goss MR, Sweat RS, Stapor PC, Peirce SM, Murfee WL. Targeting pericytes for angiogenic therapies. Microcirculation. 2014;21:345-357.

8. Fakhrejahani E, Toi M. Tumor angiogenesis: pericytes and maturation are not to be ignored. J Oncol. 2012;2012:261750.

9. Ribatti D, Nico B, Crivellato E. The role of pericytes in angiogenesis. Int J Dev Biol. 2011;55:261-268.

10. Chen WC, Baily JE, Corselli M, et al. Human myocardial pericytes: multipotent mesodermal precursors exhibiting cardiac specificity. Stem Cells. 2015;33:557-573.

11. Berger M, Bergers G, Arnold B, Hämmerling GJ, Ganss R. Regulator of g-protein signaling-5 induction in pericytes coincides with active vessel remodeling during neovascularization. Blood. 2005;105: 1094-1101.

12. Tigges U, Komatsu M, Stallcup WB. Adventitial pericyte progenitor/ mesenchymal stem cells participate in the restenotic response to arterial injury. J Vasc Res. 2013;50:134-144.

13. Dore-Duffy P, Owen C, Balabanov R, Murphy S, Beaumont T, Rafols JA. Pericyte migration from the vascular wall in response to traumatic brain injury. Microvasc Res. 2000;60:55-69.

14. Acharya G, Park K. Mechanisms of controlled drug release from drugeluting stents. Adv Drug Deliv Rev. 2006;58:387-401.

15. Shepro D, Morel NM. Pericyte physiology. FASEB J. 1993;7: 1031-1038.

16. Kim J, Chung M, Kim S, Jo DH, Kim JH, Jeon NL. Engineering of a biomimetic pericyte-covered 3D microvascular network. PLoS One. 2015;10:e0133880.

17. Andrejecsk JW, Cui J, Chang WG, Devalliere J, Pober JS, Saltzman WM Paracrine exchanges of molecular signals between alginate-encapsulated pericytes and freely suspended endothelial cells within a 3D protein gel. Biomaterials. 2013;34:8899-8908.

18. Aguilera KY, Brekken RA. Recruitment and retention: factors that affect pericyte migration. Cell Mol Life Sci. 2014;71:299-309.

19. Rajkumar VS, Shiwen X, Bostrom M, et al. Platelet-derived growth factor-beta receptor activation is essential for fibroblast and pericyte recruitment during cutaneous wound healing. Am J Pathol. 2006; 169:2254-2265.

20. Stratman AN, Schwindt AE, Malotte KM, Davis GE. Endothelialderived $\mathrm{Pdgf}-\mathrm{Bb}$ and $\mathrm{Hb}$-Egf coordinately regulate pericyte recruitment during vasculogenic tube assembly and stabilization. Blood. 2010; 116:4720-4730. 
21. Li Q, Puro DG. Adenosine activates Atp-sensitive $\mathrm{K}(+)$ currents in pericytes of rat retinal microvessels: role of $\mathrm{A} 1$ and $\mathrm{A} 2 \mathrm{a}$ receptors. Brain Res. 2001;907:93-99.

22. Park F, Mattson DL, Roberts LA, Cowley AW Jr. Evidence for the presence of smooth muscle alpha-actin within pericytes of the renal medulla. Am J Physiol. 1997;273:R1742-R1748.

23. Skalli O, Pelte MF, Peclet MC, et al. Alpha-smooth muscle actin, a differentiation marker of smooth muscle cells, is present in microfilamentous bundles of pericytes. J Histochem Cytochem. 1989;37: 315-321.

24. Nico B, Ennas MG, Crivellato E, et al. Desmin-positive pericytes in the chick embryo chorioallantoic membrane in response to fibroblast growth factor-2. Microvasc Res. 2004;68:13-19.

25. Stallcup WB, You WK, Kucharova K, Cejudo-Martin P, Yotsumoto F. NG2 Proteoglycan-dependent contributions of pericytes and macrophages to brain tumor vascularization and progression. Microcirculation. 2016;23(2):122-133.

26. Ozerdem U, Stallcup WB. Pathological angiogenesis is reduced by targeting pericytes via the $\mathrm{Ng} 2$ proteoglycan. Angiogenesis. 2004;7: 269-276.

27. Alliot F, Rutin J, Leenen PJ, Pessac B. Pericytes and periendothelial cells of brain parenchyma vessels co-express aminopeptidase N, aminopeptidase a, and nestin. J Neurosci Res. 1999;58:367-378.

28. Schlingemann RO, Oosterwijk E, Wesseling P, Rietveld FJ, Ruiter DJ. Aminopeptidase $\mathrm{a}$ is a constituent of activated pericytes in angiogenesis. J Pathol. 1996;179:436-442.

29. Kano MR, Bae Y, Iwata C, et al. Improvement of cancer-targeting therapy, using nanocarriers for intractable solid tumors by inhibition of Tgf-beta signaling. Proc Natl Acad Sci U S A. 2007;104:3460-3465.

30. Liu AY, Ouyang G. Tumor angiogenesis: a new source of pericytes. Curr Biol. 2013;23:R565-R568.

31. Nishihara T, Remacle AG, Angert M, et al. Matrix metalloproteinase-14 both sheds cell surface neuronal glial antigen 2 (NG2) proteoglycan on macrophages and governs the response to peripheral nerve injury. J Biol Chem. 2015;290:3693-3707.

32. Zhang L, Nishihara H, Kano MR. Pericyte-coverage of human tumor vasculature and nanoparticle permeability. Biol Pharm Bull. 2012; 35:761-766

33. Pietras K, Ostman A, Sjoquist M, et al. Inhibition of plateletderived growth factor receptors reduces interstitial hypertension and increases transcapillary transport in tumors. Cancer Res. 2001;61: 2929-2934.

34. Pietras K, Rubin K, Sjoblom T, et al. Inhibition of Pdgf receptor signaling in tumor stroma enhances antitumor effect of chemotherapy. Cancer Res. 2002;62:5476-5484.

35. Xian X, Hakansson J, Stahlberg A, et al. Pericytes limit tumor cell metastasis. J Clin Invest. 2006;116:642-651.

36. Ruppen J, Wildhaber FD, Strub C, et al. Towards personalized medicine: chemosensitivity assays of patient lung cancer cell spheroids in a perfused microfluidic platform. Lab Chip. 2015;15:3076-3085.

37. Loi M, Marchio S, Becherini P, et al. Combined targeting of perivascular and endothelial tumor cells enhances anti-tumor efficacy of liposomal chemotherapy in neuroblastoma. J Control Release. 2010; 145:66-73.

38. Guan YY, Luan X, Xu JR, et al. Selective eradication of tumor vascular pericytes by peptide-conjugated nanoparticles for antiangiogenic therapy of melanoma lung metastasis. Biomaterials. 2014;35:3060-3070.
39. Prakash J, de Jong E, Post E, Gouw AS, Beljaars L, Poelstra K. A novel approach to deliver anticancer drugs to key cell types in tumors using a Pdgf receptor-binding cyclic peptide containing carrier. J Control Release. 2010;145:91-101.

40. Prakash J, de Jong E, Post E, Mohammad AK, Beljaars L, Poelstra K. Targeting tumor stromal cells through a PDGF-beta receptor binding carrier. J Control Release. 2010;148:e116.

41. Karen J, Rodriguez A, Friman T, Dencker L, Sundberg C, Scholz B. Effects of the histone deacetylase inhibitor valproic acid on human pericytes in vitro. PLoS One. 2011;6:e24954.

42. Murphy EA, Shields DJ, Stoletov K, et al. Disruption of angiogenesis and tumor growth with an orally active drug that stabilizes the inactive state of Pdgfrbeta/B-Raf. Proc Natl Acad Sci U S A. 2010;107: 4299-4304.

43. Chute JP, Himburg HA. Imatinib tackles lymphoma via the PDGFR $\beta+$ pericyte. Blood. 2013;121:5107-5108.

44. Manley PW, Cowan-Jacob SW, Buchdunger E, et al. Imatinib: a selective tyrosine kinase inhibitor. Eur J Cancer. 2002;38 Suppl 5:S19-S27.

45. Miljkovic-Licina M, Hammel P, Garrido-Urbani S, et al. Targeting olfactomedin-like 3 inhibits tumor growth by impairing angiogenesis and pericyte coverage. Mol Cancer Ther. 2012;11:2588-2599.

46. Bergers G, Song S, Meyer-Morse N, Bergsland E, Hanahan D. Benefits of targeting both pericytes and endothelial cells in the tumor vasculature with kinase inhibitors. J Clin Invest. 2003;111:1287-1295.

47. Sennino B, Kuhnert F, Tabruyn SP, et al. Cellular source and amount of vascular endothelial growth factor and platelet-derived growth factor in tumors determine response to angiogenesis inhibitors. Cancer Res. 2009;69:4527-4536.

48. Lu C, Shahzad MM, Moreno-Smith M, et al. Targeting pericytes with a Pdgf-B aptamer in human ovarian carcinoma models. Cancer Biol Ther. 2010;9:176-182.

49. Chamorro-Jorganes A, Lee MY, Araldi E, et al. VEGF-induced expression of mir-17-92 cluster in endothelial cells is mediated by ERK/ELK1 activation and regulates angiogenesis. Circ Res. 2016;118(1):38-47.

50. Iacovelli R, Sternberg CN, Porta C, et al. Inhibition of the Vegf/Vegfr pathway improves survival in advanced kidney cancer: a systematic review and meta-analysis. Curr Drug Targets. 2015;16:164-170.

51. Gokcinar-Yagci B, Uckan-Cetinkaya D, Celebi-Saltik B. Pericytes: properties, functions and applications in tissue engineering. Stem Cell Rev. 2015;11:549-559.

52. Kim S, Lee H, Chung M, Jeon NL. Engineering of functional, perfusable 3D microvascular networks on a chip. Lab Chip. 2013;13:1489-1500.

53. He W, Nieponice A, Soletti L, et al. Pericyte-based human tissue engineered vascular grafts. Biomaterials. 2010;31:8235-8244.

54. Fuoco C, Sangalli E, Vono R, et al. 3D Hydrogel environment rejuvenates aged pericytes for skeletal muscle tissue engineering. Front Physiol. 2014;5:203.

55. Mendes LF, Pirraco RP, Szymczyk W, et al. Perivascular-like cells contribute to the stability of the vascular network of osteogenic tissue formed from cell sheet-based constructs. PLoS One. 2012;7:e41051.

56. Saik JE, Gould DJ, Watkins EM, Dickinson ME, West JL. Covalently immobilized platelet-derived growth factor-Bb promotes angiogenesis in biomimetic poly(ethylene glycol) hydrogels. Acta Biomater. 2011;7: 133-143.

International Journal of Nanomedicine

\section{Publish your work in this journal}

The International Journal of Nanomedicine is an international, peerreviewed journal focusing on the application of nanotechnology in diagnostics, therapeutics, and drug delivery systems throughout the biomedical field. This journal is indexed on PubMed Central, MedLine, CAS, SciSearch ${ }^{\circledR}$, Current Contents ${ }^{\circledR} /$ Clinical Medicine,

\section{Dovepress}

Journal Citation Reports/Science Edition, EMBase, Scopus and the Elsevier Bibliographic databases. The manuscript management system is completely online and includes a very quick and fair peer-review system, which is all easy to use. Visit http://www.dovepress.com/ testimonials.php to read real quotes from published authors. 